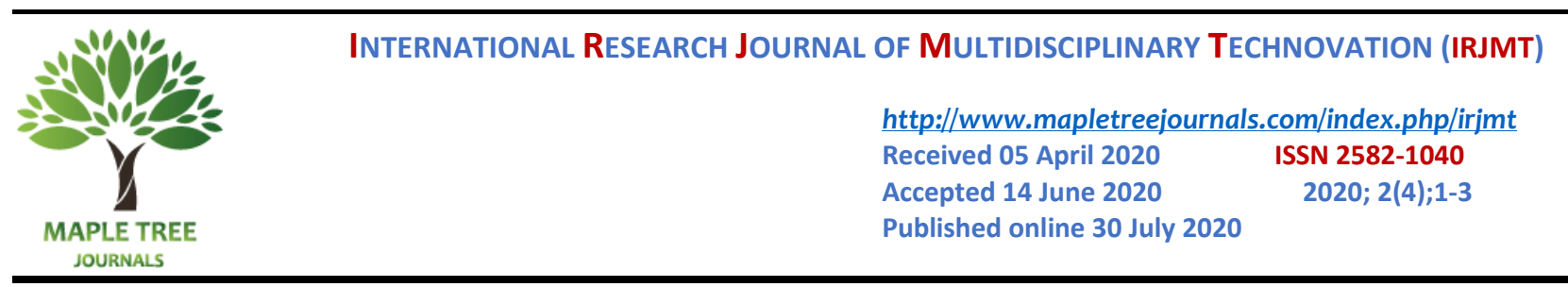

\title{
Automation by Brain Sense Through Eeg Waves
}

\author{
M. Ragavi ${ }^{1,}$ *, M.K. Subha Sri Lakshmi ${ }^{1}$ \\ ${ }^{I}$ Department of Information Technology, Velammal Collage of Engineering and Technology, Madhuri, Tamil Nadu, \\ India. \\ *Corresponding author E-Mail ID: ragaviditv@gmail.com \\ DOI: https://doi.org/10.34256/irjmt2041
}

\begin{abstract}
Brain Computer Interface (BCI) is one of the communication channels used to make an interaction between human brain and digital computer to control/operate the external devices without having any touch of muscular body part. This provides the easiness in operations and also helpful to elder and decibel people. This is useful for people who cannot operate the peripheral devices using our normal muscular body parts. The proposed system aims to control home appliances (like bulb, fanatic.) with the help of Human Attention Level which come sunder on invasive method of brains signal measurement. This attention is being measured by Neuro Sky Headset. Attention level values are ranges from 1 to 100. Attentionmeansuser' level of mental focus which occurs during intense concentration and directed (but stable) mental activity. So, to get attention values user should observe the object (or focus on to the object). For demonstration purpose here are used one bulb and one fan.
\end{abstract}

Keywords: Brain Computer Interface (BCI) System, Elec-troencephalograms (EEG), Neurosky, Non- invasive.

\section{Introduction}

This interface system is especially useful for severely disabled, or locked- in an individual with no reliable muscular control over their body parts to interact with surrounded peripherals [1$3]$. There are several such systems available and most of them require few muscular controls to be operational such as head, neck, eyes etc.

\section{Emergency Commands}

This application is mainly used for uneducated people and also used for requesting for emergency basic needs in their day-to-day life (see fig 1). Emergency commands such as
1. Food
2. Water
3. Washroom
4. Entertainment
5. Bath
6. Not feeling good
7. Medicine
8. Outdoor

The commands that we select is Spoked out as a voice command via laptop speaker 


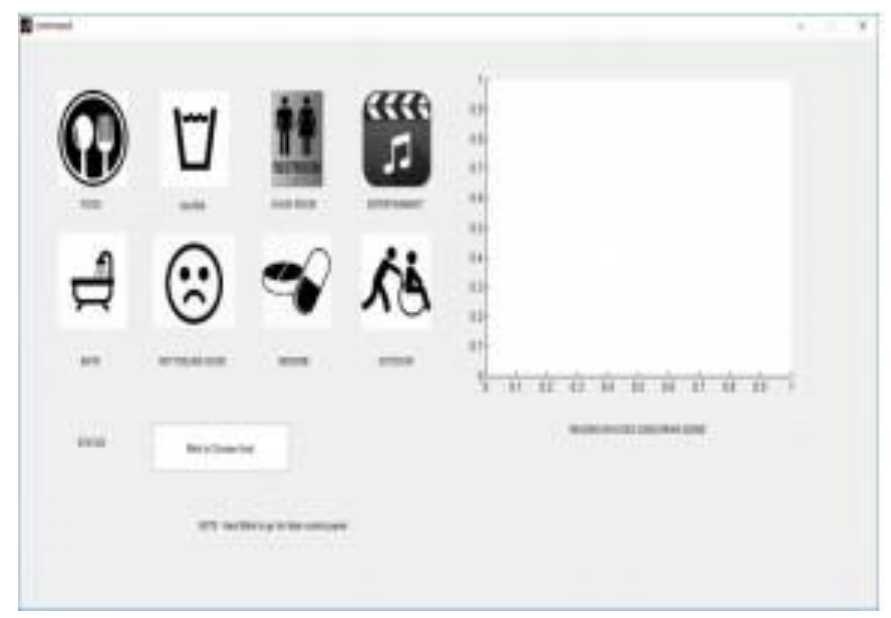

Fig 1. Emergency commands panel

\section{Main Control Panel}

All application is linked in main control panel, paralysed people can switch over from one application too there using eye blink (See fig 2). It makes more efficient to access all application by themselves.

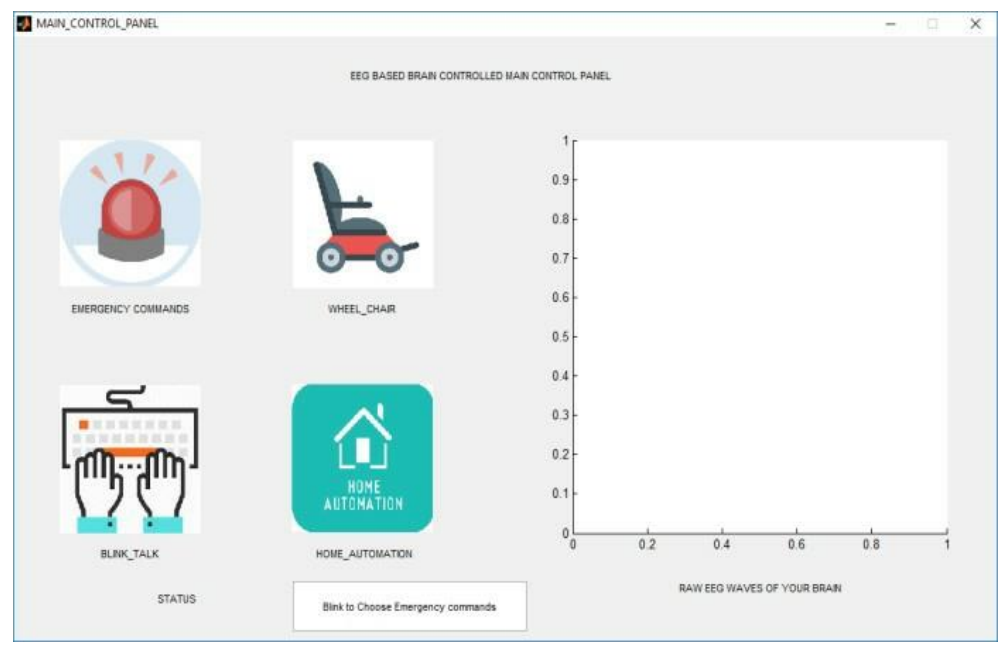

Fig 2. Main control panel for all application

\section{Neurosky Mind Wave Mobil}

It is used to measure EEG (electroencephalography) this device is non-invasive in nature Non-invasive: It is the type of having electrode in the scalp of the brain instead of injecting electrode directly in brain tissue (invasive).

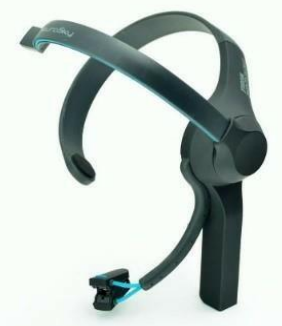

Fig 3. Neurosky Mind Wave Mobile 
It consists of 2electrode main electrode is placed in the scalp of the forehead and other is reference electrode fixed in the ear (See fig 3) [4-5].

\section{Conclusion}

The Neurosky Mind wave mobile and electrode doesn't make any harm to the brain as it is just place in the scalp. In existing model attention and meditation are used for some application. It is inspired by the wheel chair used by Stephen Hawking physicist, cosmologist. In our proposed model we merge all application with the wheel chair so that they can switch over from one application to another themselves using eye blinks.

\section{References}

[1] Lu Zheng Bi, Xin-A Fan, Yili Liu, EEG-Based Brain-Controlled Mobile Robots: A Survey, IEEE Transactions on Human-Machine Systems, 43 (2013) 161-176.

[2] W. Li, C. Jaramillo, Y. Li, (2012) Development of Mind Control System for human oid Robot through a Brain Computer Interface, In 2012 Second International Conference on Intelligent System Design and Engineering Application, IEEE, 679-682.

[3] J.R. Millan, F. Renkens, J. W. Gerstner, Non-invasive Brain-Actuated Control of a Mobile Robot by Human EEG, IEEE Transaction son Biomedical Engineering, 51 (2004) 1026-1033.

[4] H. A. Shedeed, M. F. Issa, S. M. El - Sayed, (2013) Brain EEG Signal Processing for Controlling Robotic Arm, In 2013 8th International Conference on Computational \& Experimental Engineering and Sciences, IEEE, 152-157.

[5] S. Ramesh, M. G. Krishna, M. Nakirekanti, Brain Computer Interface System for Mind Controlled Robot using Bluetooth, International Journal of Computer Applications, 104 (2014) 20-23.

\section{Acknowledgement Nil}

\section{Funding}

This study was not funded by any grant

\section{Conflict of interest}

None of the authors have any conflicts of interest to declare.

\section{About The License}

The text of this article is licensed under a Creative Commons Attribution 4.0 International License

\section{Cite this Article}

M. Ragavi, M.K. Subha Sri Lakshmi, Automation by Brain Sense Through Eeg Waves, International Research Journal of Multidisciplinary Technovation, Vol 2, Iss 4(2020) 1-3.

DOI: https://doi.org/10.34256/irimt2041 